\title{
Improvement of Vertical Diffusion Analytic Schemes Under Stable Atmospheric Conditions
}

\author{
Amela Jeričević · Željko Večenaj
}

Received: 8 January 2008 / Accepted: 24 February 2009 / Published online: 12 March 2009

(C) The Author(s) 2009. This article is published with open access at Springerlink.com

\begin{abstract}
Based on gradient transport theory or K-theory, turbulent transport in the atmosphere has long been parameterized using the eddy diffusivity. Due to its simplicity, this approach has often been applied in many numerical models but rarely tested with observations. Here, the widely used O'Brien cubic polynomial approach has been validated together with an exponential approach against eddy diffusivity profiles determined from measurements and from large-eddy simulation data in stable conditions. Verification is completed by analyzing the variability effects on pollutant concentrations of two different vertical diffusion $(K(z))$ schemes incorporated in an atmospheric chemical model. It is shown that the analytical, exponential solution agrees better with observations than the O'Brien profile and should be used henceforth in practical applications.
\end{abstract}

Keywords Air quality models $\cdot$ K-theory $\cdot$ Linear exponential approach · O’Brien profile

\section{Introduction}

Vertical diffusion is a very important parameter introduced by turbulence closure theory that represents the intensity of vertical mixing in the atmosphere. The vertical eddy diffusion coefficient $(K(z)$, where $z$ is height) is usually the main quantity in numerical models of the atmosphere for vertical distribution of different atmospheric properties and pollutants. It has been shown that vertical diffusion has significant impacts on simulated chemical concentrations (e.g. Oliviè et al. 2004; Nowacki et al. 1996; Biswas and Rao 2000). On the other hand, the evaluation of $K(z)$ is not an easy task because the diffusion coefficients cannot be measured directly, and their numerical representations are only a simplification of complex physical processes (e.g. De Foy et al. 2007).

\author{
A. Jeričević $(\varangle)$ \\ MHSC Meteorological Service, Zagreb, Croatia \\ e-mail: jericevic@ cirus.dhz.hr \\ Ž. Večenaj \\ AMGI Department of Geophysics, Faculty of Science, University of Zagreb, Zagreb, Croatia
}


Different parameterizations for $K(z)$, dependent on thermal stability in the atmospheric boundary layer (ABL), can be found in, e.g. Stull (1988), and O'Brien (1970) proposed a simple parameterization scheme used in many air quality models even today. For example, a vertical diffusion model based on the O'Brien scheme was found suitable for the simulation of distributions of a passive tracer such as ${ }^{222} \mathrm{Rn}$ (e.g. Lee and Larsen 1997), and in the Comprehensive Air Quality Model with Extensions (CAMx), an Eulerian photochemical dispersion model, used in many practical applications (ENVIRON 1998). In CAMx the O'Brien scheme is one option for the $K(z)$ calculation. The $K(z)$ scheme in CAMx has been validated and the sensitivity of carbon monoxide $(\mathrm{CO})$ and ozone $\left(\mathrm{O}_{3}\right)$ surface concentrations on the $K(z)$ values is shown in Zhang et al. (2004).

Turbulence structure under stable atmospheric conditions is an important issue in air pollution studies. Parameterizations based on the Monin-Obukhov similarity theory $(\mathrm{M}-\mathrm{O})$ in the surface layer (Monin and Obukhov 1954) are applied in atmospheric numerical models (e.g. Garratt and Pielke 1989; Best and Hopwood 2001) and used for scaling near-surface fluxes (e.g. Dias and Brutsaert 1996; Mahrt 1999; Zilitinkevich et al. 2002). Surface-layer formulations based on the $\mathrm{M}-\mathrm{O}$ theory in statically stable conditions have been validated against experimental datasets (e.g. Mahrt 1999; Pahlow et al. 2001; Poulos and Burns 2003) where significant misrepresentation of surface parameters is indicated. In practical applications, vertical resolution and turbulence parameterizations used in different numerical models often cannot realistically represent physical processes in stable conditions (e.g. Mauritsen et al. 2007). In stable conditions it is often difficult to resolve the vertical structure of the ABL, which can be very thin, with a thickness from few hundreds metres to only a few metres (e.g. Smedman 1988; Mahrt and Vickers 2006; Banta et al. 2007). Traditional methods, such as O'Brien (1970), represent $K(z)$ as a polynomial function that depends on several parameters, e.g. the surface-layer depth, which is not easy to resolve and describe in statically stable conditions (e.g. Zilitinkevich and Calanca 2000; Jeričević and Grisogono 2006; Mauritsen et al. 2007).

The main goal of our work is to introduce a robust exponential approach to the $K(z)$ calculation that is applicable in stable as well as in convective conditions. Advantages of this relatively new analytical form of $K(z)$ are confirmed with observations and large-eddy simulation (LES) data. Two different schemes have also been applied in the atmospheric chemical Unified EMEP model (Berge and Jacobsen 1998) to test their impact on the simulation of surface concentrations.

\section{Data}

\subsection{FLOSSII and CASES-99}

Composite vertical profiles for the two datasets, Fluxes over Snow-covered Surfaces II (FLOSSII) and Cooperative Atmosphere-surface Exchange Study-1999 (CASES-99), analyzed by Mahrt and Vickers (2006), were used. In FLOSSII, which took place from 1 December 2002 to 31 March 2003 in the North Park Basin of north-west Colorado, USA the 30-m tower provided seven levels of nocturnal eddy-correlation data over a grass surface, sometimes partially or completely snow covered. In CASES-99 1-month of eddy-correlation data from a 60-m tower with seven levels of eddy-correlation data over grassland in south central Kansas, USA was also analyzed. In their work authors categorize eddy diffusivities computed from class-averaged heat flux and along-wind momentum flux, and corresponding vertical gradients, according to weak and strong turbulence classes. Both classes 
correspond to stable stratification with different turbulence intensity; from very weak turbulence to the stronger turbulence stable cases. Threshold values for the definition of cases were imposed on the fine-scale velocity variance averaged over $1 \mathrm{~h}$ and then averaged over the tower layer for FLOSII and CASES-99 (Table 1; Mahrt and Vickers 2006). For illustration, in FLOSSII, threshold values of the 1 -h average of the vertical velocity variance $\left(\overline{w^{\prime} w^{\prime}}\right)$ in the weak class was $\overline{w^{\prime} w^{\prime}}=0.09 \mathrm{~m}^{2} \mathrm{~s}^{-2}$, while for the strong class $\overline{w^{\prime} w^{\prime}}=22 \mathrm{~m}^{2} \mathrm{~s}^{-2}$. For further information see Mahrt and Vickers (2006). Here only vertical eddy diffusivity profiles for the strong turbulence class determined from measurements $\left(K_{\text {meas }}\right)$ were used. Very weak conditions with intermittent turbulence are not considered, and our emphasis is on eddy diffusivities for strong turbulence classes corresponding to stable, nocturnal conditions.

\subsection{LES Data}

Since measurements cover only the lowest $30 \mathrm{~m}$ of the ABL in FLOSSII and $60 \mathrm{~m}$ in CASES99 for a thorough study it was necessary to include data covering the full vertical extension of the ABL. LES data have been found to be very useful in numerous studies of the ABL (e.g. Deardorff 1970; Wyngaard and Brost 1984; Andren et al. 1994; Kosovic and Curry 2000; Ding et al. 2001; Zilitinkevich and Esau 2003; Mauritsen et al. 2007).

In this work LES data from DATABASE64 (e.g. Esau and Zilitinkevich 2006) including a wide range of neutral and stably stratified cases are used to evaluate two different methods for the vertical diffusion calculation. DATABASE64 was chosen since it contains numerous idealized LES cases, which is an advantage compared to e.g. those from the first GEWEX Atmospheric Boundary Layer Study (GABLS, where GEWEX is the Global Energy and Water Cycle Experiment). The first GABLS intercomparison (Kosovic and Curry 2000) considers a particular idealized case only; this case corresponds to the long-lived stable class in DATABASE64.

Special classification of neutral and stable conditions according to the buoyancy (BruntVäisälä) frequency, $N=\left(\frac{g}{\theta_{0}} \frac{\partial \theta}{\partial z}\right)^{1 / 2}$ and surface heat fluxes is shown in Table 1 , and in this study we have analyzed conventionally neutral, nocturnal and long-lived stable classes. Modelled normalized profiles of mean wind, potential temperature and turbulent fluxes for each class are represented in Fig. 1. In all cases the initial temperature profile (neutral or with constant stratification), the constant background geostrophic wind, the surface roughness length and surface heat flux were defined. The conventionally neutral class has zero surface heat flux with the ABL growing against a stably stratified atmosphere. As a consequence the lower part of the ABL is well mixed, and the top capped by a stably stratified elevated inversion.

Table 1 Overview of boundary-layer classes, number of cases, ranges of the bulk Richardson number in the class and boundary-layer depths

\begin{tabular}{llllll}
\hline Class & $w \theta_{0}$ & $N$ & Number & $R_{B}$ & $H_{\text {LES }}$ \\
\hline Conventionally neutral & 0 & $>0$ & 39 & $0.005-3.59$ & $128-1652$ \\
Nocturnal & $<0$ & 0 & 31 & $0.05-3.38$ & $46-1875$ \\
Long-lived & $<0$ & $>0$ & 15 & $0.35-7.6$ & $16-507$ \\
\hline
\end{tabular}

Here $\overline{w \theta_{0}}$ is the surface heat flux and $N$ is the background Brunt-Väisälä frequency 

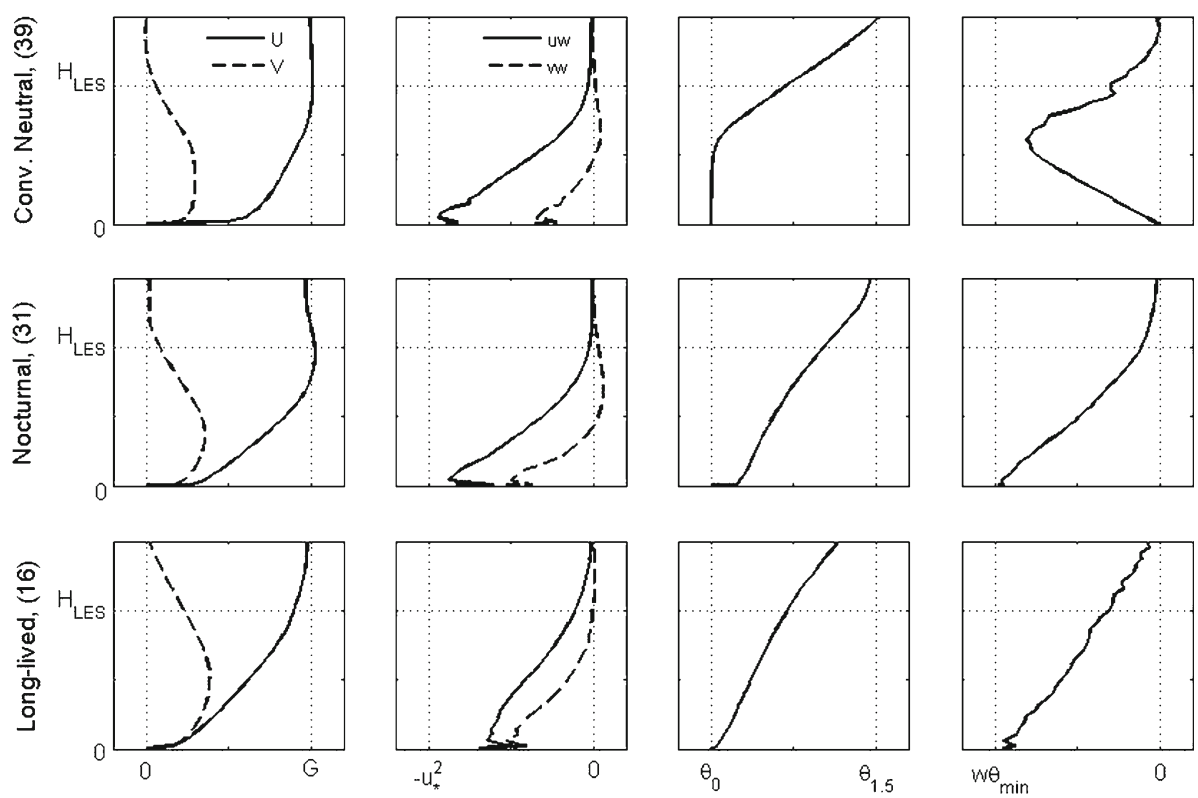

Fig. 1 Normalized average profiles from LES. The vertical normalization was done with the boundary-layer height derived from LES, $H_{\mathrm{LES}}, G$ is the geostrophic wind, $u_{*}^{2}$ is the LES total surface stress, $\theta_{0}$ is the LES total surface potential temperature, $\theta_{1.5}$ is the LES potential temperature at $1.5 H_{\text {LES }}$ and $w \theta_{\min }$ is the minimum potential temperature flux in the LES. The numbers in the brackets of the vertical axes represents the number of cases corresponding to the each analyzed stability

This case is representative of windy situations when the surface heat flux is negligible. The nocturnal boundary layer develops in a near-neutral atmosphere, with heat lost at the surface, and occurs during nighttime over land with a near-neutral residual layer present as a remnant of the daytime convective boundary layer. For the long-lived stable class, surface cooling predominates with a background stable stratification, and can be found at high latitudes over land during wintertime.

Each simulation was run for $15 \mathrm{~h}$ to achieve a quasy steady state, but not used if the chosen LES domain was smaller than 1.5 times the height of the ABL.

\subsection{The Unified EMEP Model}

The Unified EMEP model was developed at the Norwegian Meteorological Institute under the European Monitoring and Evaluation Programme (EMEP). It simulates atmospheric transport and deposition of acidifying and eutrophying compounds over Europe, as well as photo-oxidants and particulate matter (Simpson et al. 2003; Tarrasón et al. 2003). The model domain covers Europe and the Atlantic Ocean with the grid size $50 \times 50 \mathrm{~km}^{2}$, while in the vertical there are 20 terrain following layers up to $100 \mathrm{hPa}$. The Unified EMEP model uses three-hourly meteorological data from the PARallel Limited Area Model with Polar Stereographic map projection (PARLAM-PS), a dedicated version for EMEP of the HIgh Resolution Limited Area Model (HIRLAM) model (Bjorge and Skalin 1995). 


\section{Methods for Vertical Diffusion Calculation}

O'Brien (1970) developed a method for the calculation of the eddy diffusion coefficient, $K(z)$, which has been widely used in many practical applications. In this approach, $K(z)$ is calculated from the following cubic polynomial, which requires four independent parameters for its evaluation:

$$
K(z)=K_{A}+\frac{\left(z-z_{A}\right)^{2}}{(\Delta z)^{2}}\left\{K_{B}-K_{A}+\left(z-z_{B}\right)\left(K_{B}^{\prime}+2 \frac{K_{B}-K_{A}}{\Delta z}\right)\right\}
$$

where $K_{A}$ is a value of $K\left(z_{A}\right)$ at the height of the ABL, $z_{A}$, and $K_{B}$ is $K\left(z_{B}\right)$ at the height of the surface layer, $z_{B}$, the so-called constant-flux layer. The thickness of the mixed layer is $\Delta z=z_{A}-z_{B}$. Further $K_{B}^{\prime}$ is determined from:

$$
K_{B}^{\prime}=\frac{K_{B}-K_{1}}{z_{B}-z_{1}}
$$

where $z_{1}$ is the lowest measuring height and correspondingly $K_{1}=K\left(z_{1}\right)$. It is supposed that variations of $K(z)$ at height $z_{A}$ are infinitesimally small, so that $K_{A}^{\prime}=0$. From $K_{B}^{\prime}>0$ it follows that $K$ in Eq. 1 must increase monotonically with height in the constant-flux layer, and that the maximum value of $K(z),\left(K_{\max }\right)$, must occur between $z_{B}$ and $z_{A}$. In the constant-flux layer O'Brien (1970) assumed $K(z)=k u_{*} z /(1+\phi(z))$, and derived a relation for $K_{\text {max }}$ from Eq. 1 taking into account that the ABL height is much greater than the height of the surface layer; $z_{A}>>z_{B}$, and also that the strength of vertical diffusion at the top of the surface layer is significantly greater than that at the ABL height; $K_{B}>>K_{A}$. Finally after some calculation,

$$
K_{\max } \approx \frac{4}{27}\left(K_{B}+z_{A} K_{B}^{\prime}\right)
$$

at $z=(1 / 3) z_{A}$. It should be noted here that the O'Brien polynomial depends on the model vertical resolution, i.e. the number of model levels for which $K(z)$ is calculated. Therefore, the O'Brien method is physically plausible or even reasonable in unstable conditions, when $z_{A}>>z_{B}$ is satisfied. In cases of near-neutral and especially very stable conditions, when $z_{A}$ is not much higher than $z_{B}$, the applicability of the O'Brien method in numerical models is questionable. Nevertheless, it is often used and even recommended in neutral and stable conditions (e.g. Stull 1988).

Consequently, we introduce a linear-exponential method where the O'Brien thirdorder polynomial $K(z)$ is generalized into a linear-exponential function (e.g. Grisogono and Oerlemans 2002):

$$
K(z)=\left(K_{\max } e^{1 / 2} / h\right) z \exp \left(-0.5(z / h)^{2}\right)
$$

where $h$ is the height of $K_{\max }$. Comparing Eq. 1 (O'Brien), with Eq. 4 (Grisogono), one notes that an advantage of (4) in respect to (1) is that it needs only two input parameters, $K_{\max }$ and $h$. A schematic representation of all input parameters for the O'Brien as well as for the Grisogono approach is given in Fig. 2.

\subsection{Practical Determination of Input Parameters}

All input parameters for the O'Brien and Grisogono methods are described in Table 2. Input parameters for the O'Brien approach $\left(K_{A}, K_{B}, z_{A}\right.$ and $\left.z_{B}\right)$ used in Eq. 1 and for the Grisogono approach $\left(K_{\max }, h\right)$ used in Eq. 4 applied to FLOSSII and CASES-99 are determined from 


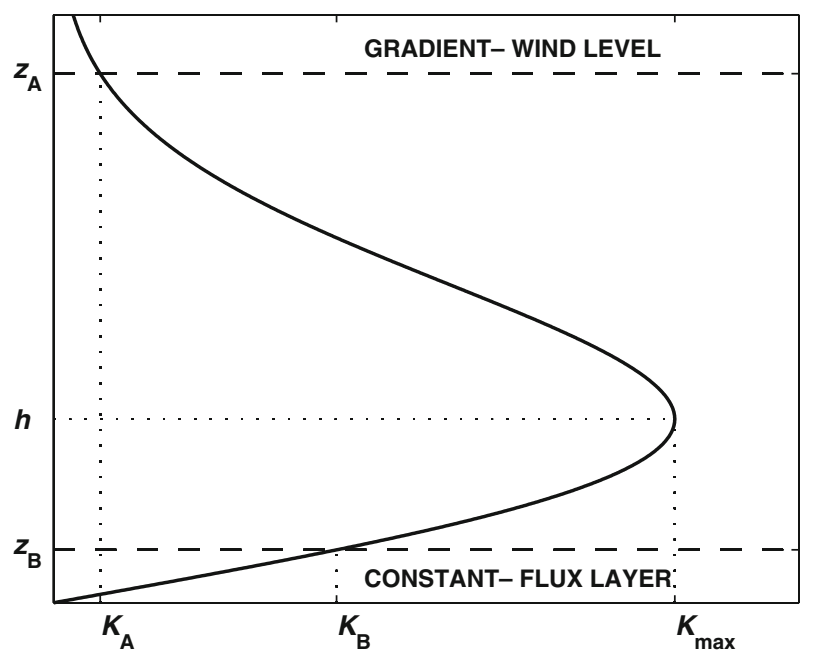

Fig. 2 Schematic representation of input variables needed for the O'Brien polynomial: $K_{A}, K_{B}, z_{A} z_{B}$ and the variables needed in the Gisogono approach: $h$ and $K_{\max }$

Table 2 Description of the input parameters used for $K(z)$ determination using the O'Brien and Grisogono methods based on FLOSSII, CASES-99 and LES data

FLOSSII and CASES-99 LES

$\begin{array}{lll}\text { O’Brien } & \\ z_{A}(\mathrm{~m}) & 10 z_{B} & \begin{array}{c}\text { Height of which } \\ T K E=0.02 T K E_{\max }\end{array} \\ z_{B}(\mathrm{~m}) & \text { Height at which } K_{\text {meas }} \text { linear profile terminates } & 0.1 z_{A} \\ K_{A}\left(\mathrm{~m}^{2} \mathrm{~s}^{-1}\right) & 0.1 & 0.1 \\ K_{B}\left(\mathrm{~m}^{2} \mathrm{~s}^{-1}\right) & K_{\text {meas }}\left(z_{B}\right) & k z_{B} u_{*} / \phi_{m}(z / L) \\ \text { Grisogono } & \text { Height at which } K_{\text {meas }} \text { reaches the } \\ h & \text { maximum } & z_{A} / C(h) \\ K_{\max } & \text { Maximum value of } K_{\text {meas }} & C(K) z_{A} u_{*}\end{array}$

Input parameters in the O'Brien function are: $z_{A}$, the ABL height, $z_{B}$, the height of the surface layer, $K_{A}$, i.e. $K(z)$ at the height of the $\mathrm{ABL}$, and $K_{B}$, i.e. $K(z)$ at the height of the surface layer. Here TKE is turbulent kinetic energy derived from the LES, $k$ is the von Karman constant $0.41, u_{*}$ is friction velocity, $L$ is the Obuhkov length and $\phi_{m}(z / L)$ is a stability function. Input parameters for Grisogono are: $h$, the height of the $K(z)$ maximum, and $K_{\max }$, the maximum of $K(z)$

experimentally defined profiles ( $K_{\text {meas }}$ ) obtained from Figs. 6 and 7 in Mahrt and Vickers (2006). Values of $z_{B}$ are at the top of the $K_{\text {meas }}$ linear profile starting from the surface, while $z_{A}$ is determined as $10 z_{B}$ assuming that the height of the surface layer is about $10 \%$ of the ABL height (e.g. Stull 1988). In this study the eddy diffusivity at the top of the ABL is set to $0.1 \mathrm{~m}^{2} \mathrm{~s}^{-1}$, i.e. $K_{A}=0.1 \mathrm{~m}^{2} \mathrm{~s}^{-1} . K_{B}$ is taken at height $z_{B}$ while $K_{\max }$ and $h$ needed for the Grisogono profile calculations are also taken from measurements, as the maximum value of $K_{\text {meas }}$ and its height.

From the LES data $z_{A}$ is determined from profiles of turbulent kinetic energy (TKE) calculated from the LES, while $z_{B}$ and $K_{A}$ are defined in the same way as in the FLOSSII and 
CASES-99 cases. The value of $K_{B}$ is calculated using stability functions $\phi_{m}(z / L)$ according to e.g. Stull (1988):

$$
K_{B}=\frac{k z u_{*}}{\phi_{m}(z / L)}
$$

where the Obukhov length $(L)$, and the friction velocity $\left(u_{*}\right)$ are taken from the LES. Next, $\phi_{m}$ is defined for stable conditions as:

$$
\phi_{m}=1+4.7 z / L
$$

and for unstable conditions as,

$$
\phi_{m}=(1-15 z / L)^{-1 / 4} \text {. }
$$

From the LES data, input parameters needed in Eq.4, i.e. the maximum value of the vertical diffusion coefficient, $K_{\max }$, and its height $h$ are calculated according to:

$$
\begin{aligned}
K_{\max } & =C(K) z_{A} u_{*}, \\
h & =z_{A} / C(h),
\end{aligned}
$$

where the $C(K)$ and $C(h)$ represent constants empirically estimated from the LES data.

Definition of the $K_{\max }$ in Eq. 7 includes non-local effects through the ABL height, which is an integral atmospheric property, while the local turbulence property is included in the friction velocity $u_{*}$. The ABL height is an integral property that relates surface processes to upper processes in the ABL and thus implicity contains non-local effects. The surface is assumed to be the main source of turbulence, with the fluxes mainly driven by the surface heat and friction. Furthermore, the ABL height is strongly related to surface heating and cooling over land, since it acquires smaller values, from a few metres to a few hundred metres in stable conditions, to a few thousand metres in strongly unstable conditions.

For every LES run $K_{\max }$ and $h$ are determined from the LES $K(z)$ profiles and from the profiles determined with the Grisogono method with predefined initial constant values, $C_{0}(K)$ and $C_{0}(h)$, providing the basis for the calculation $K_{\max }(\mathrm{LES}) / K_{\max }$ (Grisogono). Averaged ratios were used to find an optimal coefficient needed in Eqs. 7 and 8:

$$
C(K)=\frac{1}{N} \sum_{n=1}^{N}\left(\frac{K_{\max }(\mathrm{LES})}{K_{\max }(\text { Grisogono })}\right)_{n} C_{0}(K)
$$

where the index $n$ denotes the number of the LES runs $n=1, \ldots, 86$. Coefficients calculated with this procedure are presented in Table 3 . Based on the coefficients calculated from the LES data in stable conditions, the maximum value of eddy diffusivity for momentum, $K_{m}$, is greater than that of heat, $K_{h}$, by a factor of two.

Table 3 Initial and calibrated constants used for determination of input parameters $K_{\max }$ and $h$ used for the calculation of $K_{m}$ and $K_{h}$ with the Grisogono method

\begin{tabular}{lllll}
\hline & $C_{0}(K)$ & $C(K)$ & $C_{0}(h)$ & $C(h)$ \\
\hline$K_{m}\left(\mathrm{~m}^{2} \mathrm{~s}^{-1}\right)$ & 0.125 & 0.13 & 2 & 1.52 \\
$K_{h}\left(\mathrm{~m}^{2} \mathrm{~s}^{-1}\right)$ & 0.125 & 0.06 & 2 & 3.73 \\
\hline
\end{tabular}




\section{Results}

The O'Brien polynomial approach and the Grisogono analytical approach are compared in order to evaluate their performance in stable and near-neutral conditions. Vertical profiles of $K(z)$ have been analyzed for two different datasets: FLOSSII and CASES-99 observations, and from the LES data, DATABASE64.

Further, the Grisogono method is implemented in the atmospheric chemical Unify EMEP model and validated against the operational O'Brien scheme based on the surface daily $\mathrm{NO}_{2}$ concentrations calculated for January and July 2001. Verification is completed by analyzing variability effects on pollutant concentrations for two different $K(z)$ schemes incorporated in the atmospheric chemical model.

\subsection{Results for FLOSII and CASES-99}

Vertical profiles of $K_{m}$ and $K_{h}$ are calculated with Eqs. 1 and 4 for the strong turbulence class from FLOSSII and from CASES-99, see Fig. 3. These calculated profiles are compared with $K_{\text {meas }}$. The O'Brien method, Eq. 1, overestimates the height of $K_{m}$ for FLOSSII (Fig. 3a) and the maximum value of $K_{h}$ for CASES-99 (Fig. 3d), while Grisogono, Eq. 4, agrees well with the $K_{\text {meas }}$. An overestimation of $h$ or $K_{\max }$ with Eq. 1 is a consequence of a misrepresentation of surface-layer parameters used in the O'Brien approach. While the height of $K_{\max }$ calculated with the O'Brien method agrees with the CASES-99 measurements, the magnitude of
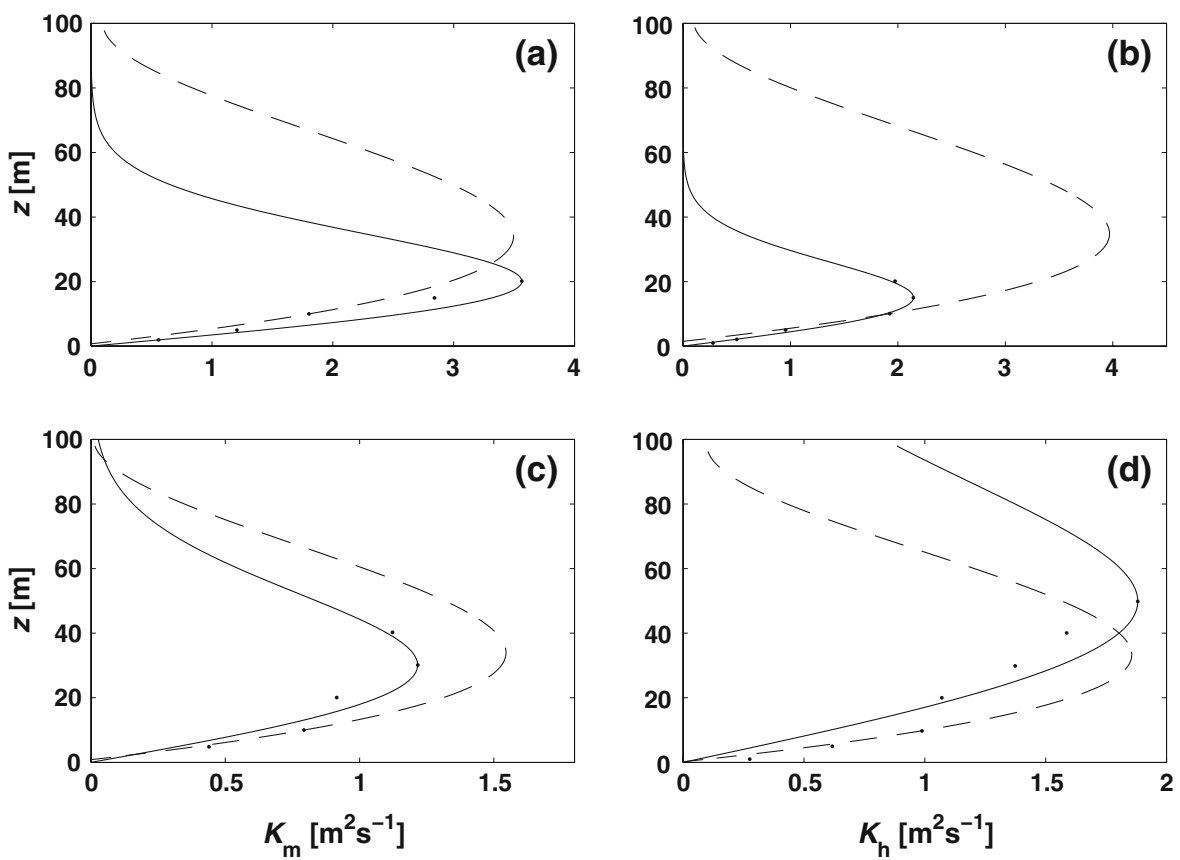

Fig. 3 Vertical profiles of eddy diffusivity estimated from the composite vertical structure for the strong turbulence class for FLOSSII: momentum (a) and heat flux (b), and CASES-99: momentum (c) and heat flux (d). Dashed line is O'Brien third-order polynomial (1), solid line is Grisogono (4) and the dots represent the measurements digitalized from Figs. 6 and 7 in Mahrt and Vickers (2006) 
$K_{\max }$ is overestimated (Fig. 3c). For the same data the maximum of $K_{h}$ was well represented with the O'Brien approach, although its height was somewhat underestimated (Fig. 3d). The misrepresentation of $h$ and $K_{\max }$ with the O'Brien method may lead to either an overestimation or underestimation of simulated concentrations when (1) is applied in various air quality models. Note that profiles of $K_{h}$ and $K_{m}$ determined from the FLOSSII and CASES-99 data are different, while both the O'Brien and Grisogono methods are non-local and mainly depend on the magnitude and height of $K_{\max }$.

\subsection{Results Deploying the LES Data}

Around 90 large-eddy simulations, including a wide range of neutral and stably stratified cases, are used to evaluate two different methods for vertical diffusion calculation. In Fig. 4 an intercomparison of different vertical diffusion schemes against six randomly chosen LES $K(z)$ profiles in conventionally neutral conditions is shown. In the shear driven $\mathrm{ABL}, K_{m}$ is the stronger and dominant factor while $K_{h}$ experiences lower magnitudes and a greater spread in values. Better agreement of the Grisogono method is apparent while the O'Brien profiles tend to underestimate $K_{m}$ (Fig. 4a-c) and overestimate $K_{h}$ (Fig. 4d-f). Note the good agreement for the $K(z)<K_{\max }$, i.e. in the surface layer, for both methods. The overestimation of $K_{h}$ with the O'Brien method is in agreement with the results for FLOSSII in Fig. 3b.

Figure 5 represents nocturnal stable conditions, where the O'Brien polynomial function tends to underestimate the LES data for $K_{m}$ (Fig. 5a-c) by underpredicting the mechanical mixing in the surface layer. In cases of weaker turbulence with $K_{\max }$ between 1 and
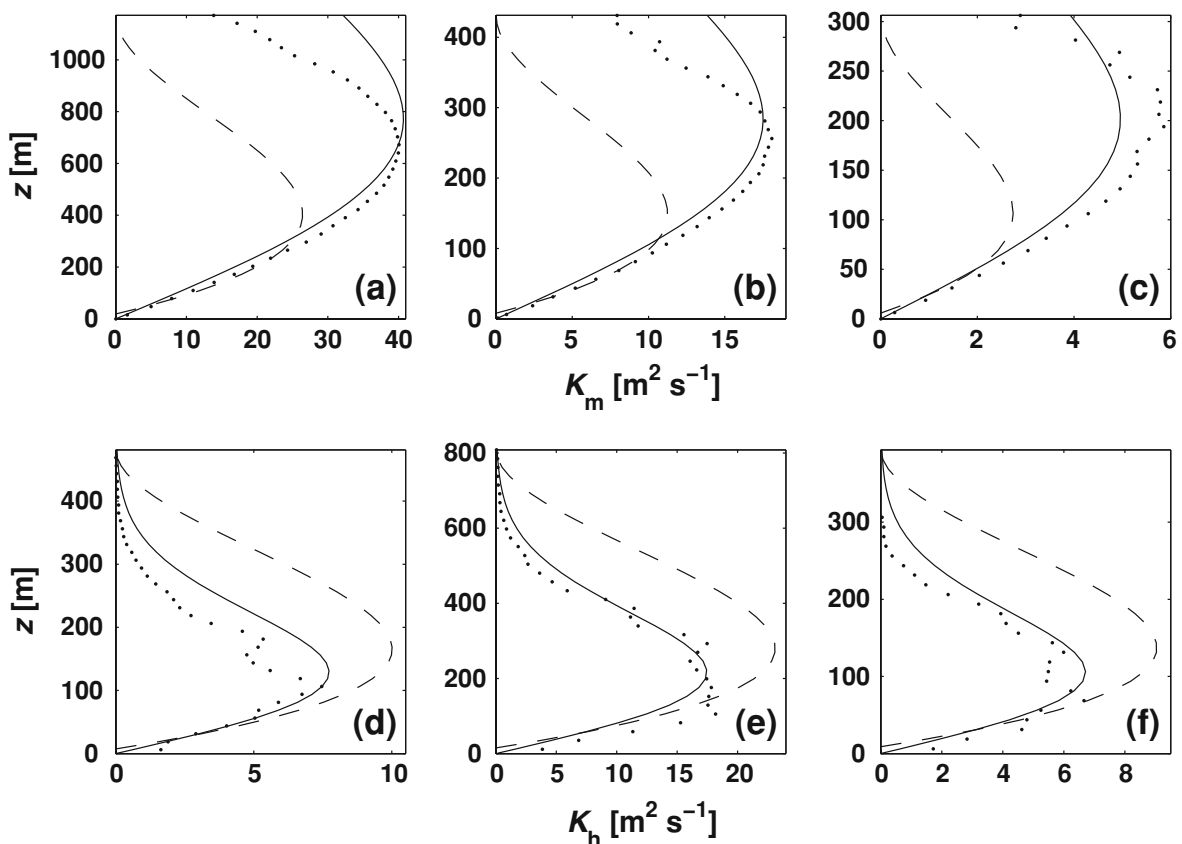

Fig. 4 Vertical diffusion for momentum in selected runs (a)-(c) and heat (d)-(f) profiles calculated with O'Brien (dashed) and Grisogono method (solid) against $K(z)$ from the LES data (dots) for conventionally neutral conditions 

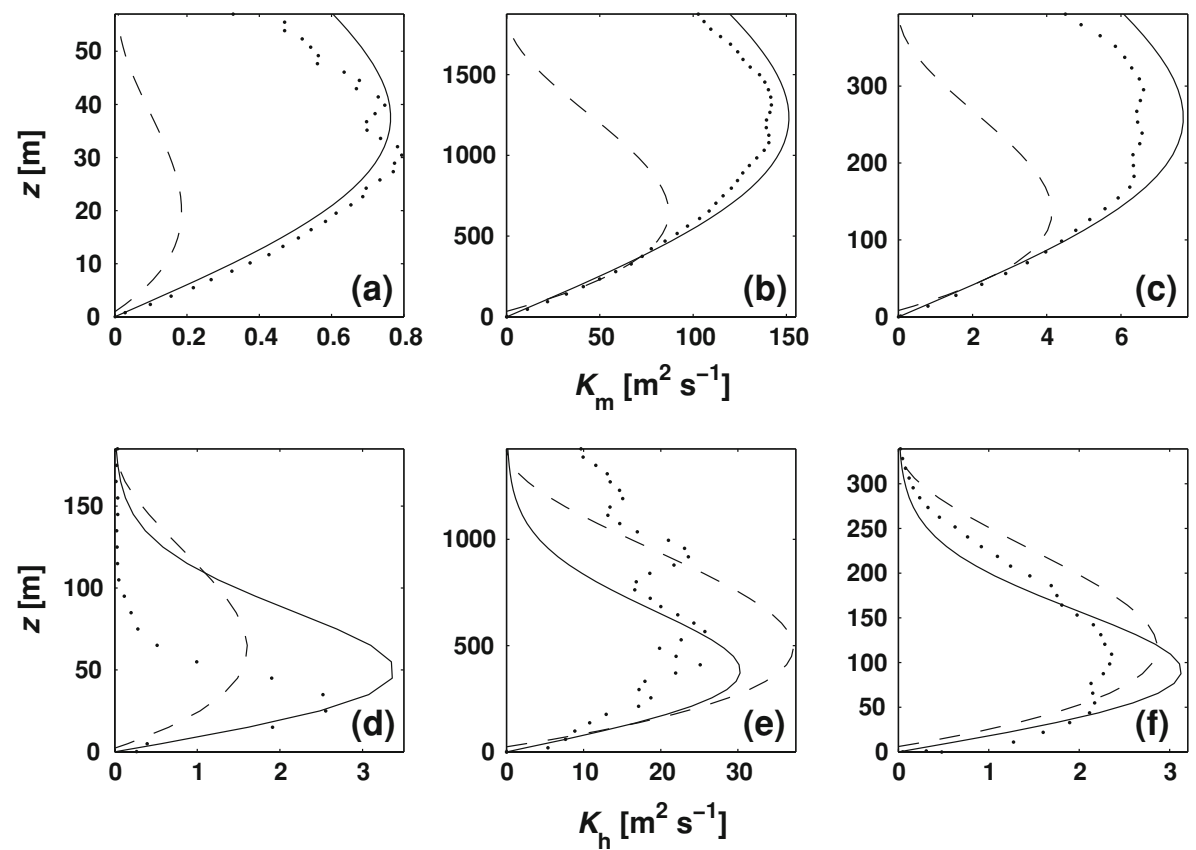

Fig. 5 Same as in Fig. 4, but for the nocturnal conditions

$3 \mathrm{~m}^{2} \mathrm{~s}^{-1}, K_{h}$ calculated with the O'Brien method is underestimated (Fig. 5d, e) while it is overestimated for stronger turbulence cases (Fig. 4d-f). Although the O'Brien and Grisogono methods agree better for $K_{h}$, especially for the stronger turbulence cases, the Grisogono method prevails.

In the case of strong stability in Fig. 6 results are similar for $K_{m}$. For $K_{h}$ both methods overpredict compared to the LES data (Fig. $5 \mathrm{~d}-\mathrm{f}$ ), probably because $K_{h}$ in these conditions is very small and cannot be described with 'standard' parameterization methods; moreover, the overall scatter is high: turbulence is intermittent, vertical fluctuations are pronounced, and $K_{h}$ does not have a continuous vertical distribution. Similar results are found in Mahrt and Vickers (2006) for extremely weak mixing in stable conditions in FLOSSII. In the latter situation, typical $K$ theory most probably fails due to intermittency, nonstationarity and measurement problems.

\subsection{Implementation of the Grisogono Method in the Unified EMEP Model}

The vertical turbulent diffusion profile has many applications, and it is especially important in the modelling of air quality since it drives the vertical distribution of pollutants and other chemical species. The new vertical diffusion scheme is applied in the Eulerian chemical model EMEP in order to evaluate its practical performance. The operational version for the $K(z)$ calculation in the EMEP model described in Mihailovic and Alapaty (2007) is based on the O'Brien scheme for convective conditions and the Blackadar (1979) formulation in stable conditions.

In the EMEP model, the coefficients based on the LES data (see Table 3), which are needed in the formulation of $K_{\max }$ and $h$ (see Eqs. 5 and 6a, 6b), are implemented. Friction velocity 

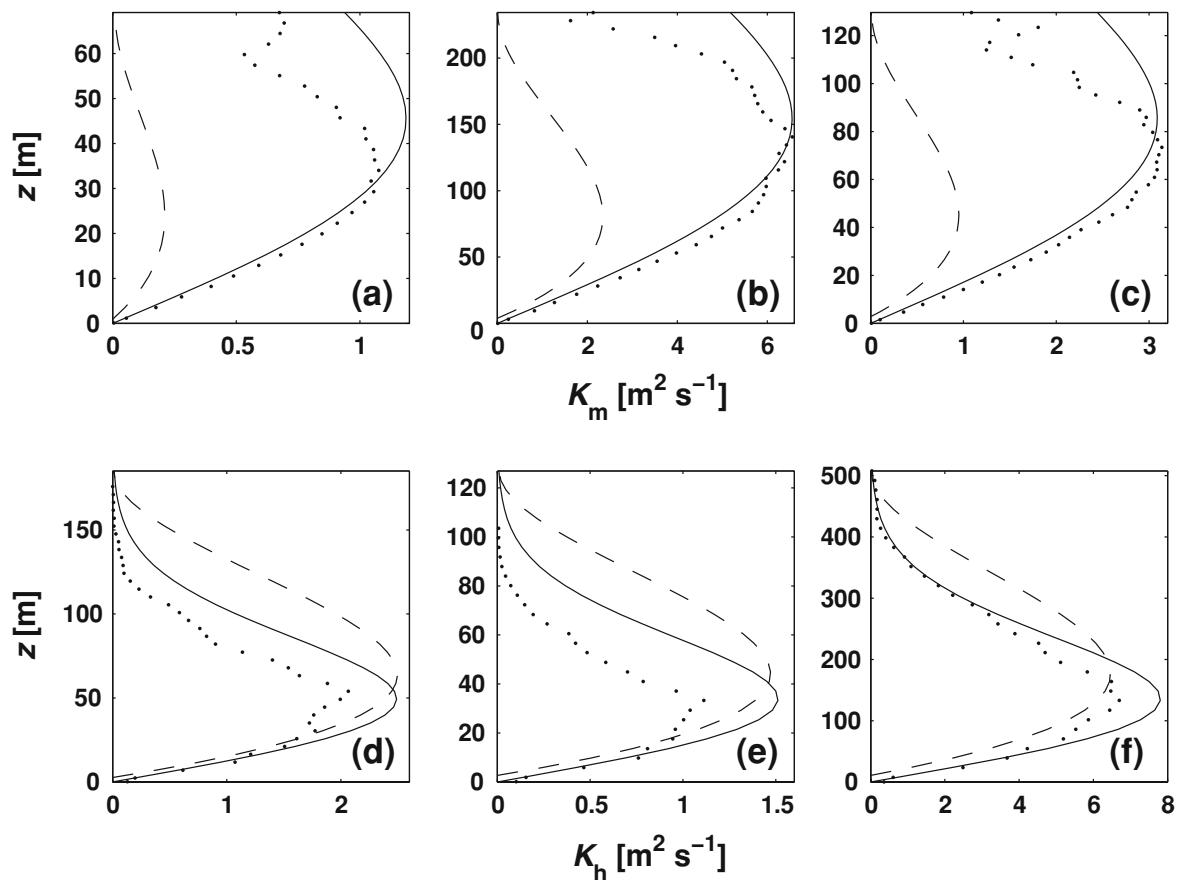

Fig. 6 Same as in Fig. 4, but for the long-lived stable conditions

is taken from the numerical weather prediction (NWP) model HIRLAM and the ABL height is determined based on the bulk Richardson number method as in Jeričević and Grisogono (2006).

Modelled daily surface $\mathrm{NO}_{2}$ concentrations for January and July 2001 are compared to measurements at EMEP stations at different locations in Europe. For January the number of stations used was 46 and in July it was 47. In January, Fig. 7a, b, the correlation coefficient for the Grisogono method, $r_{\text {Grisogono }}$, was 0.59 and for the O'Brien method, $r_{\text {O_Brien }}=0.56$, while BIAS values (Fig. 7a, b) was $14 \%$ and $22 \%$ for the methods of Grisogono and O'Brien, respectively. The overestimation of the O'Brien method against the measurements was higher than for the Grisogono method, implying the same result as that indicated more strongly by FLOSSII and CASES-99 data shown earlier. In July (Fig. 7c, d) the correlation coefficient generally decreases in the model, but the Grisogono method still performs somewhat better, even in the summer period when more convective and unstable situations were present. It should be pointed out that the computing efficiency of the EMEP model with a new scheme is improved (not shown), though, needless to say, in such a complex model it is very difficult to improve the model overall performance by more than a few percent while deploying a single parametrization change.

\section{Conclusions}

An evaluation of empirical approaches for determining the $K(z)$ profiles in stable conditions shows that the O'Brien profile (O'Brien 1970) produces deviations in $h$ and $K_{\max }$ for both 

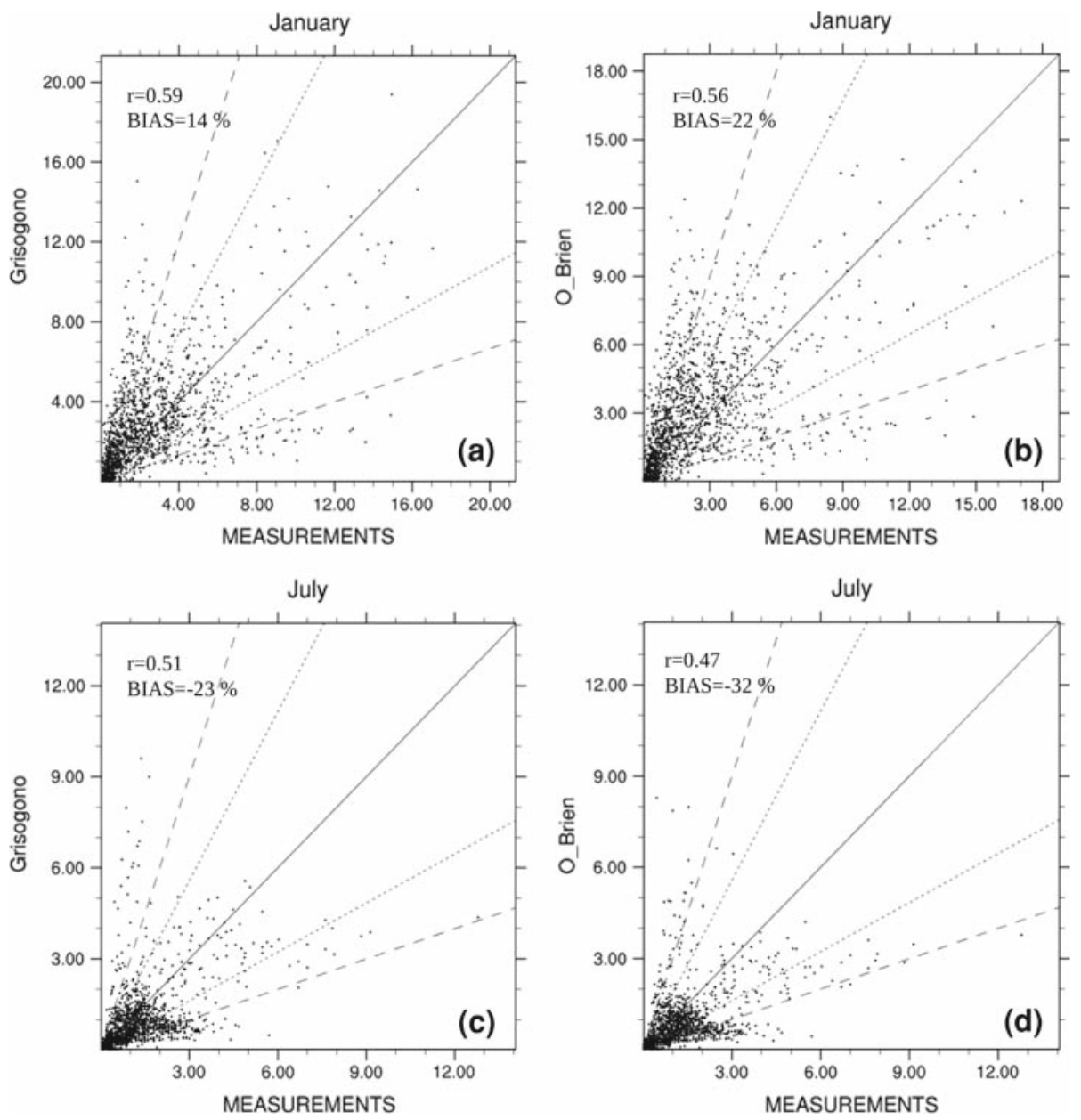

Fig. 7 Scatter plots between the measured and modelled surface daily $\mathrm{NO}_{2}$ concentrations calculated with the EMEP model with two different vertical diffusion schemes: (a) Grisogono for January, (b) O'Brien for January, (c) Grisogono for July and (d) O’Brien in July 2001

FLOSSII and CASES-99 observations; when applied in chemical models it leads to either an underestimation or overestimation in simulated pollutant concentrations.

Better defined parameters in the O'Brien profile, especially for the surface-layer height, $z_{B}$, and the corresponding magnitude of $K(z)$ in the surface layer, based on $\phi_{m}$ or on more advanced methods, would lead to a better adjustment to measurements. Nevertheless, it is not easy to overcome the problem of "model not meeting measurements", since the ABL structure near the surface is exceedingly complex while measurements are sparse in space and time. In the practical applications both $K(z)$ schemes use input values utilized from the meteorological driver (here NWP model HIRLAM is used) and their accuracy is constrained with the NWP model performance, with the ability to realistically represent atmospheric motion, and with the model's vertical and horizontal resolution, and physical parameterizations used. 
In this work LES from DATABASE64 (Esau and Zilitinkevich 2006), including a wide range of neutral and stably stratified cases, were used to evaluate two different methods for the $K(z)$ calculation. Coefficients calculated from the LES data in stable conditions show that the maximum value of $K_{m}$ is larger than that for $K_{h}$ by a factor of two, with the corresponding Prandtl number $\left(P r=K_{m} / K_{h}\right), P r \approx 2.2$. An increase of $P r$ with increasing stability is also found in other studies, implying a more efficient transport of momentum than for heat (e.g. Zilitinkevich and Esau 2007; Mauritsen et al. 2007; Grisogono et al. 2007). The LES data provide the basis for determination of generally applicable coefficients, both in stable and unstable conditions, used for calculation of the two input parameters, $K_{\max }$ and $h$, in the method of Grisogono (Grisogono and Oerlemans 2002).

The Grisogono approach, gives a better agreement with $K(z)$ determined from the measurements and from LES in stable conditions, than that of O'Brien; furthermore, it is also more technically convenient since only two input variables are demanded instead of four. Therefore, the Grisogono scheme for $K(z)$ determination is recommended for practical applications, yielding an improvement in overall model results.

Acknowledgements Authors are grateful to Branko Grisogono for many valuable advises and suggestions; furthermore, we thank the reviewers for several important recommendations. This work is supported by the EMEP4HR project under number 175183/S30 funded by the Research Council of Norway, and by projects BORA 119-1193086-1311 and 004-1193086-3036 of the Croatian Ministry of Science, Education and Sport.

Open Access This article is distributed under the terms of the Creative Commons Attribution Noncommercial License which permits any noncommercial use, distribution, and reproduction in any medium, provided the original author(s) and source are credited.

\section{References}

Andren A, Brown A, Graf J, Moeng CH, Mason PJ, Nieuwstadt FTM, Schumann U (1994) Large-eddy simulation of neutrally-stratified boundary layer: a comparison of four computer codes. Q J Roy Meteorol Soc 120:1457-1484. doi:10.1002/qj.49712052003

Banta RM, Mahrt L, Vickers D, Sun J, Balsley BB, Pichugina YL, Williams EJ (2007) The very stable boundary layer on nights with weak low-level jets. J Atmos Sci 64:3068-3090. doi:10.1175/JAS4002.1

Berge E, Jacobsen HA (1998) A regional scale multi-layer model for the calculation of long-term transport and deposition of air-pollution in Europe. Tellus 50:205-223. doi:10.1034/j.1600-0889.1998.t01-2-00001.x

Best MJ, Hopwood WP (2001) Modelling the local surface exchange over grass-field site under stable conditions. Q J Roy Meteorol Soc 127:2033-2052. doi:10.1002/qj.49712757610

Biswas J, Rao T (2000) Uncertainties in episodic ozone modelling stemming from uncertainties in the meteorological fields. J Appl Meteorol 40:117-136. doi:10.1175/1520-0450(2001)040<0117:UIEOMS>2.0. $\mathrm{CO} ; 2$

Bjorge D, Skalin R (1995) PARLAM—The parallel HIRLAM version of DNMI. Research Report 27: ISSN: 0332-9879. Norwegian Meteorological Institute, Oslo, Norway, 49 pp

Blackadar AK (1979) Modelling pollutant transfer during daytime convection. In: Fourth symposium on atmospheric turbulence diffusion and air quality. American Meteorological Society, Reno, NV, pp 443-447

Deardorff JW (1970) Convective velocity and temperature scales for the unstable planetary boundary layer and for Raleigh convection. J Atmos Sci 29:91-115. doi:10.1175/1520-0469(1972)029<0091:NIONAU>2. $0 . \mathrm{CO} ; 2$

de Foy B, Lei W, Zavala M, Volkamer R, Samuelsson J, Mellqvist J, Galle B, Martinez AP, Grutter M, Molina L (2007) Modelling constraints on the emission inventory and on vertical diffusion for CO and $\mathrm{SO}_{2}$ in the Mexico city metropolitan area using solar FTIR and zenith sky UV spectroscopy. Atmos Chem Phys 7(3):781-801

Dias NL, Brutsaert W (1996) Similarity of scalars under stable stratification. Boundary-Layer Meteorol 80:355-373. doi:10.1007/BF00119423

Ding F, Arya SP, Lin YL (2001) Large-eddy simulations of the atmospheric boundary layer using a new subgrid-scale model. Part II: weakly and moderately stable cases. Environ Fluid Mech 1:49-69. doi:10. 1023/A:1011543715591 
ENVIRON (1998) User's guide to the comprehensive air quality model with extensions (CAMx) version 2.00. ENVIRON International Corporation, 101 Rowland Way, Suite 220, Novato, California, 265 pp

Esau I, Zilitinkevich SS (2006) Universal dependences between turbulent and mean flow parameters is stably and neutrally stratified planetary boundary layers. Nonlinear Process Geophys 13:122-144

Garratt JR, Pielke RA (1989) On the sensitivity of mesoscale models to surface-layer parametrisation constants. Boundary-Layer Meteorol 48:377-387. doi:10.1007/BF00123060

Grisogono B, Oerlemans J (2002) Justifying the WKB approximation in pure katabatic flows. Tellus, Ser A, Dyn Meterol Oceanogr 54:453-462. doi:10.1034/j.1600-0870.2002.201399.x

Grisogono B, Kraljević L, Jeričević A (2007) The low-level katabatic jet height versus Monin-Obukhov height. Q J Roy Meteorol Soc, Part B 133(629):2133-2136

Jeričević A, Grisogono B (2006) The critical bulk Richardson number in urban areas: verification and application in a numerical weather prediction model. Tellus, Ser A, Dyn Meterol Oceanogr 58:19-27. doi:10. 1111/j.1600-0870.2006.00153.x

Kosovic B, Curry JA (2000) A quasi steady state of a stable stratified atmospheric boundary layer: a large-eddy simulation study. J Atmos Sci 57:1052-1068. doi:10.1175/1520-0469(2000)057<1052:ALESSO>2.0. $\mathrm{CO} ; 2$

Lee HN, Larsen RJ (1997) Vertical diffusion in the lower atmosphere using aircraft measurements of ${ }^{222} \mathrm{Rn}$. J Appl Meteorol 36:1262-1270. doi:10.1175/1520-0450(1997)036<1262:VDITLA >2.0.CO;2

Mahrt L (1999) Stratified atmospheric boundary layers. Boundary-Layer Meteorol 90:375-396. doi:10.1023/ A: 1001765727956

Mahrt L (2007) The influence of nonstationarity on the turbulent flux-gradient relationship for stable stratification. Boundary-Layer Meteorol 125:245-264. doi:10.1007/s10546-007-9154-0

Mahrt L, Vickers D (2006) Extremely weak mixing in stable conditions. Boundary-Layer Meteorol 119:19-36. doi:10.1007/s10546-005-9017-5

Mauritsen T, Svensson G, Zilitinkevich S, Esau I, Enger L, Grisogono B (2007) A total turbulent energy closure model for neutral and stably stratified atmospheric boundary layers. J Atmos Sci 64:4113-4126. doi:10.1175/2007JAS2294.1

Mihailovic DT, Alapaty K (2007) Intercomparison of two K-schemes: local versus nonlocal in calculating concentrations of pollutants in chemical and air-quality models. Environ Model Softw 22:1685-1689. doi:10.1016/j.envsoft.2007.03.002

Monin AS, Obukhov AM (1954) Basic laws of turbulent moxing in the surface layer of the atmosphere. Trudy Geofiz Inst Akad Nauk SSSR 151:163-187

Nowacki P, Samson PJ, Sillman S (1996) Sensitivity of urban airshed model (UAM-IV) calculated air pollutant concentrations to the vertical diffusion parametrisation during convective meteorological situations. J Appl Meteorol 35:1790-1803. doi:10.1175/1520-0450(1996)035<1790:SOUAMI>2.0.CO;2

O'Brien JJ (1970) A note on the vertical structure of the eddy exchange coefficient in the planetary boundary layer. J Atmos Sci 27:1213-1215. doi:10.1175/1520-0469(1970)027<1213:ANOTVS>2.0.CO;2

Oliviè DJL, van Velthoven PFJ, Beljaars ACM (2004) Evaluation of archived and off-line diagnosed vertical diffusion coefficients from ERA-40 with ${ }^{222}$ Rn simulations. Atmos Chem Phys 4(9/10):2313-2336

Pahlow M, Parlange MB, Porté-Agel F (2001) On Monin-Obukhov similarity in the stable atmospheric boundary layer. Boundary-Layer Meteorol 99:225-248. doi:10.1023/A:1018909000098

Poulos GS, Burns SP (2003) An evaluation of bulk Ri-based surface layer flux formulas for stable and very stable conditions with intermittent turbulence. J Atmos Sci 60:2523-2537. doi:10.1175/ 1520-0469(2003)060<2523:AEOBRS>2.0.CO;2

Simpson D, Fagerli H, Jonson JE, Tsyro S, Wind P, Tuovinen JP (2003) Unified EMEP model description. Status Report 1, Part I, Oslo, Norway, 104 pp

Smedman AS (1988) Observations of a multi-level turbulence structure in a very stable atmospheric boundary layer. Boundary-Layer Meteorol 44:231-253. doi:10.1007/BF00116064

Stull RB (1988) An introduction to boundary layer meteorology. Kluwer Academic Publishers, Dordrecht, $666 \mathrm{pp}$

Tarrasón L, Simpson D, Fagerli H, Jonson JE, Tsyro S, Wind P (2003) Transboundary acidification and eutrophication and ground level ozone in Europe, Unified EMEP model validation. Status Report 1, Part II, Oslo, Norway, $170 \mathrm{pp}$

Wyngaard JC, Brost RA (1984) Top-down and bottom-up diffusion of a scalar in the convective boundary layer. J Atmos Sci 41:102-112. doi:10.1175/1520-0469(1984)041<0102:TDABUD>2.0.CO;2

Zhang Y, Pun B, Wu SY, Vijayaraghavan K, Seigneur C (2004) Application and evaluation of two air quality models for particulate matter for a southeastern U.S. episode. J Air Waste Manag Assoc 54:1478-1493

Zilitinkevich S, Calanca P (2000) An extended theory for the stably stratified atmospheric boundary layer. Q J Roy Meteorol Soc 126:1913-1923. doi:10.1256/smsqj.56617 
Zilitinkevich S, Esau IN (2003) The effect of baroclinicity on the equilibrium depth of neutral and stable planetary boundary layers. Q J Roy Meteorol Soc 129:3339-3356. doi:10.1256/qj.02.94

Zilitinkevich SS, Esau IN (2007) Similarity theory and calculation of turbulent fluxes at the surface for the stably stratified atmospheric boundary layer. Boundary-Layer Meteorol 125:193-205. doi:10.1007/ s10546-007-9187-4

Zilitinkevich SS, Baklanov A, Rost J, Smedman A-S, Lykosov V, Calanca P (2002) Diagnostic and prognostic equations for the depth of the stably stratified Ekman boundary layer. Q J Roy Meteorol Soc 128:25-46. doi:10.1256/00359000260498770 